\title{
Dominance-related contributions to collective territory defence are adjusted according to the threat
}

Jenny E. York*1,2 Katrina J. Wells ${ }^{1}$ Andrew J. Young ${ }^{1}$

${ }^{1}$ Centre for Ecology \& Conservation, University of Exeter, Penryn Campus, Penryn, U.K. ${ }^{2}$ Department of Zoology, University of Cambridge, Cambridge, U.K.

Received 24 April 2019

Initial acceptance 7 June 2019

Final acceptance 7 August 2019

MS number 19-00218

*Correspondence: J. E. York, Department of Zoology, Downing Street, University of Cambridge, Cambridge CB2 3EJ, U.K.

E-mail address: jenny.e.york@gmail.com

1

2

3 Across diverse societies, group members benefit from the cooperative maintenance of a

4 shared territory (a public good). How such public goods are maintained has received

6 extensive interest, yet individual contributions to cooperative territory defence remain poorly understood. Recent theory predicts that, in groups with social hierarchies, privileged individuals will contribute most to competition with rival groups as they benefit most from defence of the territory. Here, we investigated whether dominant individuals contribute more to territory defence in a group-territorial bird in which dominants monopolize within-group reproduction: the white-browed sparrow-weaver, Plocepasser mahali. Using simulated territorial intrusions, we demonstrate that dominants contributed significantly more than subordinates to territory defence. We also found that individual contributions were adjusted 
13 according to threat: males of both social classes significantly and similarly increased their

14 contributions to defence in response to a high threat (playback of an unfamiliar pair's duet,

15 rather than that of a neighbouring pair), which was associated with a stronger collective

16 response by the group. Thus, while dominants contributed most as predicted by the

17 asymmetry in benefits, subordinates did increase contributions when they were needed most

18 (in small groups and under greater threat). Contributions by subordinates when needed most

19 also highlights that dominants could still benefit substantially from tolerating the presence of

20 subordinates despite their overall lower contributions. Our results show that public goods can

21 be maintained despite unequal contributions and highlight the potential importance of

22 context-dependent behavioural flexibility in mitigating collective action problems.

24 Keywords: animal societies, collective action problem, cooperation, free riding, free-rider problem, individual contributions, social evolution, territory defence, behavioural flexibility, 26 plasticity

In human societies, individual contributions to public goods (a benefit available to all group

29 members) are often a legal or moral requirement enforced by punishment, yet in animal

30 societies, evidence of punishment is relatively rare (Arseneau-Robar et al., 2018; Bshary \&

31 Bshary, 2010; Clutton-Brock \& Parker, 1995; Fehr \& Fischbacher, 2004; Heinsohn \& Packer, 1995; Johnson, 2005; Raihani, Grutter, \& Bshary, 2010; Raihani, Thornton, \& Bshary, 2012;

33 Riehl \& Frederickson, 2016; Sigmund, et al., 2010; West \& Gardner, 2004). What

34 mechanism stabilizes cooperative contributions to public goods sufficiently for collective

35 action (and the resulting public good) to persist despite selection for free riding (cheating) in

36 animal societies has been much debated (Dugatkin, 1997; Nunn, 2000; Nunn \& Lewis, 2001;

37 Raihani et al., 2012; Riehl \& Frederickson, 2016). Olson (1965, page 35) suggested that high- 
status individuals will contribute the most, while lower status individuals gain benefits

without paying the full cost: 'the exploitation of the great by the small'. More recently, theoretical models (Gavrilets \& Fortunato, 2014) have been developed that formalize the prediction that dominant individuals should contribute more to the maintenance of public goods while subordinates should be more likely to free-ride, because the dominant individuals benefit disproportionately more from the maintenance of the public good. Indeed, in many animal societies socially dominant individuals do stand to reap greater benefits from the maintenance of public goods, such as a shared territory, as they often breed at substantially higher rates than their subordinates (Hager \& Jones, 2009; Keller \& Reeve, 1994). However, the role that social dominance plays in governing individual variation in contributions to public goods in animal societies has received little empirical attention

49 (Heinsohn \& Packer, 1995; Mares, Young, \& Clutton-Brock, 2012; Nunn, 2000).

Group territory defence provides an opportunity for testing theoretical predictions about the role of within-group social dominance in determining individual contributions to public goods (Heinsohn \& Packer, 1995; Mares et al., 2011; Mares et al., 2012). Territory defence is widespread across group-living species, and while all individuals may benefit from contributing to maintenance of the shared territory (access to resources, safety from predators and more efficient foraging; Ridley et al., 2008), dominant individuals frequently monopolize the reproductive opportunities (Hager \& Jones, 2009; Keller \& Reeve, 1994). Contributions to territory defence are also likely to entail costs (energy, time), including a risk of harm to oneself via physical injury or even fatality (Heinsohn \& Packer, 1995; Mares et al., 2012; van Schaik, 1996), leading to the prediction that subordinates should withhold risky contributions

60 given their lower expected benefits from the maintenance of the public good (Gavrilets \&

61 Fortunato, 2014). Indeed, studies of a number of species have reported dominance-related differences in contributions to territorial defence, including ring-tailed lemurs, Lemur catta, 
and several other primate species (Cords, 2007; Kitchen \& Beehner, 2007; Nunn \& Deaner, 2012), lions, Panthera leo (Heinsohn \& Packer, 1995) and feral domestic dogs, Canis lupus familiaris (Bonanni, Valsecchi, \& Natoli, 2010). Furthermore, individual contributions are negatively associated with group size in capuchins, Cebus capucinus (Crofoot \& Gilby, 2012) and feral domestic dogs (Bonanni et al., 2010), lending some empirical support to the prediction that low-rank individuals should be more likely to withhold contributions when in larger groups (Gavrilets \& Fortunato, 2014; Olson, 1965).

It has long been suggested that the cooperative contributions of subordinate group members to territory defence may have played a role in selection for dominants to tolerate the presence of subordinates, and hence for group living to evolve (Ekman \& Griesser, 2002; Riehl \& Frederickson, 2016; Woolfenden \& Fitzpatrick, 1978; potentially acting in concert with other benefits of grouping; Griesser et al 2017). However, if socially dominant individuals contribute most heavily to the maintenance of public goods while their subordinates contribute little, this has the potential to undermine the utility to dominants of tolerating the presence of subordinates on the territory, given the potential costs of sharing resources (Ekman \& Griesser, 2002; Woolfenden \& Fitzpatrick, 1978). One potential mechanism that could resolve this problem is if subordinate individuals adjust their contributions to territory defence according to the level of threat to the shared territory, investing more when the threat is greatest. Few studies have examined whether individual contributions are adjusted according to the scale of the threat (Heinsohn \& Packer, 1995), but evidence that individuals are more likely to contribute when in smaller groups could be interpreted as investment in cooperative contributions when they are most needed to defend the shared resource (Bonanni et al., 2010; Crofoot \& Gilby, 2012). 
88 Here, we investigated the role of social status and the level of threat in governing individual contributions to territorial defence in cooperatively breeding white-browed sparrow-weavers, Plocepasser mahali mahali. This species is a year-round territorial, cooperatively breeding passerine that is common throughout sub-Saharan Africa (Harrison, York, \& Young, 2014; York, Young, \& Radford, 2014). They live in groups of 2-12 individuals in which a single dominant pair monopolize within-group reproduction and subordinates of both sexes contribute to a range of cooperative activities including territory defence (Collias \& Collias, 1978; Harrison, et al., 2013a; Harrison, et al., 2013b; Walker, York, \& Young, 2016). Groups aggressively defend their territory from intrusions by individuals, pairs and neighbouring groups using duets (the dominant pair) or vocal choruses (typically the dominant pair plus at least one other group mate) that will then escalate to chasing and physical aggression (Lewis, 1982; Walker, York et al., 2016; Wingfield, Hegner, \& Lewis, 1992; York, 2012). Typical group territorial behaviours exhibited by white-browed sparrow-weavers during interactions between a resident group and one or more individuals from outside the group include rapid movement up to a vantage point and gathering in close proximity to other members of the group, followed by loud duet or chorusing vocalizations by at least two of the assembled resident group members at any one time (Collias \& Collias, 1978; Collias \& Collias, 2004). Previous studies of a more northerly subspecies, $P$. m. pectoralis, suggest that dominant individuals may indeed play a larger role in territory defence than their subordinates

107 (Wingfield et al., 1992; Wingfield \& Lewis, 1993), but the cooperative contributions of 108 subordinates and their context dependence have yet to be investigated directly. Specifically, we addressed two main questions: (1) does social status predict individual 111 contributions to group territory defence in accordance with individual dominance-related 112 payoffs from contributions (i.e. do dominant individuals contribute more than subordinates) 
and (2) when faced with territory intrusions that differ in threat level, do subordinate

114 individuals positively adjust their contributions (i.e. increase their contributions when the

115 threat level is higher)? To address this second aim, we exploited variation in intruder threat

116 level known as the 'dear-enemy' effect (Christensen \& Radford, 2018; Temeles, 1994).

117 Territory residents are frequently less responsive to intrusions by neighbouring territory

118 holders than they are to unfamiliar intruders, a pattern that is thought to arise in part because

119 unfamiliar intruders represent a greater territory threat to residents than do established

120 residential neighbours. Based on this, we carried out a paired within-individual repeated

121 measures playback experiment with two threat level treatments: a 'low-threat' neighbouring

122 pair duet and a high-threat' non-neighbouring pair duet. We predicted that, given the

123 differential reproductive payoff of defending their territory, dominant individuals would

124 show greater individual contributions than subordinates. We also predicted that, while

125 subordinates would contribute less than dominants, they should increase their cooperative

126 contributions under simulated intrusion by non-neighbours, which may represent a greater

127 threat of territory takeover. If subordinates do increase their contributions when they are

128 needed most, individual subordinates may also be more likely to contribute to the collective

129 territorial response to intrusions when their group size is small (Crofoot \& Gilby, 2012;

130 Gavrilets \& Fortunato, 2014; Olson, 1965), and so we also exploited natural variation in the

131 size of the focal resident groups in our data to investigate this prediction.

\section{Methods}

\section{General methods}

135 Data were collected between September-October 2012 and March-April 2013 from a colour-

136 ringed population of cooperatively breeding white-browed sparrow-weavers in an area of

137 approximately $1.5 \mathrm{~km}^{2}$ at Tswalu Kalahari Reserve $\left(27^{\circ} 16^{\prime} \mathrm{S}, 22^{\circ} 25^{\prime} \mathrm{E}\right)$, South Africa 
138 (Harrison et al., 2014; York et al., 2014). All birds were fitted with a single metal ring and

139 three colour rings for individual identification, under SAFRING licence 1444, and were

140 semihabituated to observation (Walker et al., 2016). The study population forms a single

141 contiguous block of adjoining territories of 30-40 groups that have been monitored since

142 2007. Group composition information (number and identity of individuals) was determined

143 by weekly monitoring observation sessions and targeted captures of the group. The dominant

144 bird of each sex was determined by weekly monitoring of dominance-related aggressive,

145 displacement and reproductive behaviours (Harrison et al., 2013; York, et al., 2016). Adult

146 males and females can be readily distinguished from about 6 months of age as males have

147 black beaks while females have paler pinkish beaks (Harrison et al., 2014). Group size was

148 determined using group composition data from routine weekly monitoring and confirmed at

149 the time of data collection for each simulated territory intrusion (see below). None of the

150 groups were actively breeding (laying, incubating, provisioning nestlings) at the time of the

151 stimulated intrusions or playback trials (based on routine monitoring (Harrison et al., 2014)

152 and confirmation on the week of the trial). The study comprised two discrete data collection

153 approaches: in the first we characterized status-related differences in individual contributions

154 using intrusions by unfamiliar pairs, that is, 'standardized simulated territorial intrusions',

155 and in the second we experimentally manipulated the perceived threat level posed by the

156 simulated intrusion 'threat level experiment' (York, 2019).

\section{Standardized simulated territorial intrusions}

158 Natural intergroup interactions are unpredictable, relatively infrequent and occur rapidly,

159 making them challenging to study. Therefore, to collect standard data on individual

160 contributions to territory defence, we performed simulated territorial intrusions (STIs) at

161 group territories $(N=27)$ using a portable loudspeaker (Jawbone, Jambox) placed at a height

162 of $1.5 \mathrm{~m}$ on the main sleeping roost tree on the focal group's territory (to represent a maximal 
threat to the resident group), with the speaker oriented in the direction of the foraging social

164 group. The aim of these STIs was to assess dominance-related differences in individual

165 contributions to a standard intrusion. The duet of a non-neighbouring pair was broadcast by

166 triggering a playback track when all members of the group were foraging on the ground

167 within approximately $10 \mathrm{~m}$ of the loudspeaker. Some groups were challenged with an STI

168 more than once, to obtain some estimates of individual consistency in contributions towards

169 STIs (see Results).

\section{$170 \quad$ Playback stimuli}

171 The playback audio tracks were produced using CoolEditPro 2.0 (Syntrillium Software

172 Corporation, Phoenix, AZ, U.S.A.) from natural duet recordings $(N=13)$, each given by a

173 resident dominant pair in response to a standard duet playback (recorded from a dominant

174 pair in a non-neighbouring group) at a distance of approximately $10 \mathrm{~m}$ using a Sennheiser

175 ME66 directional microphone with a K6 power module (2004 Sennheiser) and a Marantz

176 PMD660 solid-state recorder (D and M Holdings Inc., Kawasaki, Japan) in 48 kHz, 32-bit

177 WAV file format. We used playback to collect these recordings to ensure that (1) the duet

178 stimuli recorded for this study were all produced under a standardized social context, and (2)

179 all playback stimuli used in this study represent duets given in an interactive context. The

180 recordings collected from pairs duetting in response to playback as described above were

181 then used to create the stimulus playback tracks as follows. Each playback track was 3 min

182 long, consisting of eight repetitions of a natural duet at $20 \mathrm{~s}$ intervals (typical production rate

183 during encounters). Playback tracks were broadcast at an amplitude of $85 \mathrm{dBA}$ (at $1 \mathrm{~m}$ ),

184 which is comparable to natural duets which were measured (using a Voltcraft SL100 digital

185 sound level meter, Voltcraft, Barking, U.K.) at an average of $65 \mathrm{dBA}$ at $10 \mathrm{~m}$ (based on the

186 inverse square law of sound intensity reduction over distance). 
189 Observational data (168 observations of 122 birds during 39 STIs at 27 social groups) were 190 dictated and recorded on a DM550 Olympus recorder (ME15 Olympus microphone) by one 191 observer (J.Y.) during the 3 min simulated intrusion, while continuously observing the social 192 group using a field scope. In response to simulated intrusion, invariably two or more of the terrestrially foraging social group moved to an elevated position, close to one another,

194 became vigilant and began a vocal response. Two response metrics were derived for each simulated intrusion based on individual behaviours: (1) the identities of the individuals that contributed to the first response (those that immediately moved to an elevated position, close to other responding group mates and began a duet or chorus vocal response lasting 2-8 s); (2)

198 the identities of the individuals that contributed at all during the trial: those that contributed during the first response plus those individuals that subsequently joined the response (i.e. moved close to the group members involved in the first response) at any subsequent point during the remaining 3 min period of the simulated intrusion, as further duets or choruses were produced by the assembled individuals, but the remaining group mates (if any; 'noncontributors') continued to forage on the ground. There were four cases where it was unknown whether specific individuals contributed during the first response by the group (as not all group members could be identified confidently due to the dynamic nature of the response in this large group); therefore, these missing observations did not contribute to the

207 behavioural response data set (168/172 observations were used in analyses), but these

208 individual birds were nevertheless present during the STI and therefore contributed to 209 determining the overall group size for the two individuals confidently identified to be

210 contributing. Throughout the trials, any acts of intragroup aggression that could be deemed as

211 'punishment' (a bird chased off the territory, displaced from a foraging or perching location,

212 pecked at, other physical aggression or full fights where one individual pins another 
213 individual to the floor and aggressively pecks the other; Collias \& Collias, 1978; Harrison et

214 al., 2014) were actively searched for in the observations.

\section{Threat level experiment}

217 We carried out a paired within-individual repeated measures design experiment to investigate 218 whether individual contributions to territorial defence are adjusted in response to the level of

219 threat experienced. We focused this experiment on males because our initial results in response to STIs (see below) highlighted no sex difference in contributions; therefore, it is reasonable to expect that males' responses in this experiment would be representative of both sexes, and logistical constraints meant that it was not feasible to monitor both males and females. Each focal group contained one or more subordinate males and a dominant male, and where more than one subordinate male was present, the oldest was selected for focal observations along with the dominant male. Focal groups were selected based on having a neighbouring group that was a pair with no subordinates, so that the simulated intrusion of this pair would be naturalistic, and because an intrusion by an unfamiliar pair represents the founding or annexing of territory by a pair forming a new group. The size of the focal groups was three to five individuals, which provided a manageable number of individuals to track during observations, and increased the probability of our being able to measure contributions by subordinates (given that the probability of subordinates contributing declines with increasing group size; Fig. 1). Immediately prior to each experiment, we verified that all group members were present as expected based on routine monitoring as described above.

At each focal group $(N=12)$, a loudspeaker was placed at a height of $1.5 \mathrm{~m}$ in a tree at least $20 \mathrm{~m}$ from the focal group's main roost tree, in the direction of a neighbouring group's territory and the same position was marked and used for both of the treatments conducted at 
each focal group. Playbacks were broadcast by remotely triggering a playback track $10 \mathrm{~m}$

239 from the group, when all members of the group were foraging on the ground within

240 approximately $10 \mathrm{~m}$ of the loudspeaker. Presentation order of the threat level treatments was

241 alternated across groups (to balance for order of presentation effects) and the two treatments

242 were presented on consecutive days (to reduce any influence of changes in within-group

243 dynamics or environmental conditions), and at the same time of day for a given focal group.

244 All trials were carried out between 0600 and 1100 hours.

\section{Playback stimuli}

247 The playback audio tracks for the threat level experiment were all created using recordings

248 from natural pairs (i.e. 'dominant' pairs that lacked subordinate group members). For the experiment, each focal group that was to receive playbacks was assigned a 'neighbour' (low threat) playback track and a 'non-neighbour' (high threat) playback track. The 'neighbour' playback stimuli were recorded from the focal group's neighbouring pair. The 'nonneighbour' playback stimuli were selected for a focal group based on (1) the distance between the groups (at least three territories away) and (2) ensuring that no focal group member was likely to have had sustained contact with either individual of the pair from which the recording was made (based on known periods of group membership in all of the groups concerned). Playback stimuli were created as described above, except that in this experiment each stimulus track consisted of the sequence of the first five natural duet phrases produced by the source pair when responding to an unfamiliar duet playback, to maintain identifying information in the natural sequence from that pair. Playback stimuli were broadcast at a standardized amplitude (as above). 
263 Observational data were collected by dictation by two observers (J.Y. and K.W.) during the

264 playback trial. Each observer followed one predetermined individual male, either the

265 dominant male or the oldest male subordinate in the group. For a given focal group, the two

266 observers followed the same individual for both playback treatments, but between focal

267 groups the observers alternated whether they followed the dominant or the subordinate

268 individual, to avoid observer bias. The focal males were observed throughout the 3 min trial

269 and until $8 \mathrm{~min}$ had elapsed since the trial was initiated (by which point the majority of

270 individuals had ceased showing territorial behaviour and returned to foraging). Four response

271 measures were recorded for each trial. We recorded two measures of individual male

272 contribution to territory defence: (1) the latency to first movement response by the focal male

273 (moving up to an elevated position having ceased foraging on the ground, immediately

274 followed by vocal contributions) and (2) the latency to resume foraging after the onset of the

275 playback trial. We also recorded two measures of overall group level response to the

276 territorial intrusion, to confirm the predicted stronger overall response to the higher threat

277 stimuli: (3) the proportion of the group that contributed to the first chorus by the group and

278 (4) the duration of the first chorus by the group (where more than three individuals

279 contributed to the vocal response; Collias \& Collias, 2004). If more than half of the

280 contributions to the first chorus could not be confidently attributed to individual group

281 members, the trial was abandoned (no data were used from this attempt in the analyses), and

282 the group was revisited for both treatments a week later. Throughout the trials, we noted any

283 acts of intragroup aggression that could constitute 'punishment' (a bird chased off the

284 territory, displaced from a foraging or perching location, pecked at, other physical aggression

285 or full fights where one individual pins another individual to the floor and aggressively pecks

286 the other; Collias \& Collias, 1978; Harrison et al., 2014). 


\section{Statistical analysis}

289 All analyses were conducted in R 3.2.5 (R Development Core Team, 2015). We fitted mixed-

290 effects models (Bates, Maechler, \& Bolker, 2014) including all terms of interest (full model).

291 The significance of each explanatory variable was then determined by testing for the change

292 in deviance in the fit of the model when that specific term was removed from the full model,

293 unless otherwise stated below (Forstmeier \& Schielzeth, 2011). Model assumptions were

294 checked and, where appropriate, met the assumptions of normality of residuals, and did not

295 show unacceptable levels of overdispersion, zero inflation and heteroscedasticity unless

296 otherwise stated (R package 'DHARMa'; Hartig, 2016).

297

298

\section{$<$ H3 $>$ Standardized simulated territorial intrusions}

299 Two generalized linear mixed-effects models (GLMMs) with binomial error (logit-link

300 function) were used to analyse individual contributions to territory defence in response to

301 standard STIs. The following terms were specified in both models: social status (subordinate

302 or dominant), sex (male or female) and group size (total number of birds in the group at that

303 time) and the status*group size interaction. In model 1, the binary response term was

304 'contributed to first response: Yes/No', and in model 2 the binary response term was

305 'contributed at all during trial: Yes/No'. Both models contained multiple observations of

306 particular individuals and observations of multiple individuals from the same social group, so

307 'bird ID' and 'social group' were both fitted as random terms. The random term 'social

308 group' was dropped from both the full models to avoid unreliable effect estimates caused by

309 model convergence failure when the term was included alongside the fixed effect of 'group

310 size'. In both cases, removing this random term caused negligible reduction in explanatory

311 power $(P=0.99)$; therefore, exclusion of the term was deemed justified in producing a more

312 robust model. 


\section{Threat level experiment}

315 Analysing the effects of social status and threat level on individual contributions to territorial

316 responses required an analytical approach that can cope with censored data (a continuous

317 response term 'capped' at one or both ends of the distribution due to the sampling method).

318 Specifically, while the two latency variables (latency to first response and latency to return to

319 foraging) typically contained absolute values below the total observation time, in some cases

320 the focal event had not occurred by the end of the observation period, necessitating the use of

321 an analytical approach that can use both the latency information contained in these 'censored'

322 events and the shorter absolute latency values typically obtained. Mixed-effects survival

323 models (MESM) with Cox proportional hazards (Therneau, 2015; package 'Coxme') were

324 used because they can cope with this type of censored data and random terms can be fitted.

325 One model was used for each response term 'latency to first response' and 'latency to return

326 to foraging'. In both cases, the fixed terms were 'treatment' (neighbour or non-neighbour

327 playback stimulus) and 'social status' (subordinate or dominant) and the 'treatment*social

328 status' interaction. The random terms 'bird ID' and 'group ID' were included to account for

329 repeated measures from the same individuals and social groups. To test for the effects of the

330 terms 'social status' and 'treatment', the 'treatment*'social status' interaction was necessarily

331 first removed from the full model.

333 To analyse group level responses to the two experimental treatments two additional analyses

334 were performed. A GLMM with a binomial error structure was used to investigate whether

335 the proportion of group members that responded during the first vocal chorus response to the

336 playback was predicted by treatment. The response term was the number of birds that did and

337 the number of birds that did not respond during the first group response, with 'group ID' 
included as a random term to account for repeated measures. A linear mixed-effects model (LMM) with normal error distribution was used to investigate whether the duration (s) of the

340 first vocal chorus produced by the group during the first response to the playback was

341 predicted by treatment (neighbour, non-neighbour), with 'group ID' included as a random 342 term.

\section{Results}

345 Responses to simulated intrusions were qualitatively similar to responses to natural intrusions

346 or interactions with individuals from other social groups. Typical group territorial behaviours

347 of white-browed sparrow-weavers during interactions between a resident group and one or more individuals from outside the group included rapid movement up to a vantage point and gathering into close proximity to other members of the group, followed by loud duet or chorusing vocalizations by at least two of the assembled resident group members at any one time, as previously described (Collias \& Collias, 1978; Collias \& Collias, 2004; Lewis, 1982).

Standardized simulated territorial intrusions

Behavioural responses (of 122 individuals) to the simulated territorial intrusions (duets from non-neighbouring pairs broadcast at 27 social group territories) revealed a marginal interactive effect between group size and social status on the probability of individual contributions to the first territorial response (Table 1), and no evidence of a sex difference in individual contributions (Table 1), when analysed following a full-model approach. Model predictions show that male and female subordinates in a small group of three were $62 \%$ and $69 \%$ (respectively) more likely to contribute to first responses than those in a group of eight,

362 while dominants were highly likely to contribute regardless of group size, and so this is likely 
to be a biologically meaningful difference, albeit of statistically borderline significance (Fig.

364 1). Given the marginally significant $P$ value and the effect size (Table 1, Fig. 1), we interpret

365 the possible biological importance of the interaction with some caution (Amrhein, Greenland,

$366 \&$ Mcshane, 2019). Of primary interest to our core question, subordinates were significantly

367 less likely to contribute to the first response than dominants, as predicted (Table 1, Fig. 1).

368 Looking at the effect of group size on each social class separately, among dominant

369 individuals the probability of contributing to the first response was unrelated to group size

$370\left(\chi^{2}{ }_{1}=0.35, P=0.56\right.$; data set restricted to dominants only; Fig. 1$)$, while among subordinates,

371 the probability of contributing to the first response decreased with increasing group size $\left(\chi^{2}{ }_{1}=\right.$

$37213.48, P<0.001$; data set restricted to just subordinates; Fig. 1). Furthermore, by restricting

373 the data set to only the first STI at a group, we can rule out the possibility that the results

374 from the full data set are driven by habituation or carryover effects (status*group size

375 interaction: $\chi^{2}{ }_{1}=8.07, P=0.005$; status: $\chi^{2}{ }_{1}=32.2, P<0.001$; group size: $\chi^{2}{ }_{1}=7.66, P=$ $3760.005)$.

378 The probability of an individual subsequently contributing at any point during the response to an STI was not significantly predicted by any of the fitted terms (Table 1), as the majority of individuals did eventually join the response. In this case, absolute model estimate values should be treated with some caution, because the model was one-inflated due to $82 \%$ of

382 individuals contributing at some point during the trial. Despite being observed as present with 383 the group during the trials, $18 \%$ of individuals (notably, exclusively subordinates) failed to contribute at all. A high variance estimate for the random term bird identity in the full model $(365.6 \pm 19.12)$ suggests that individuals were consistent in their responses; for those with repeated measures during different STI sessions (32 individuals with 2-4 observations per

387 individual), $81 \%$ responded with the same response type (either contributing or not 
contributing at all during the session), with only six individual birds showing variation in response type across separate trials.

390

391 While it is clear that dominant individuals are especially aggressive and will forcefully repel

392 both conspecifics and heterospecifics from their territory rapidly and with great vigour (York, n.d. Unpublished raw data) and engage in dominance interactions with subordinates in the group (Collias \& Collias, 1978; Harrison et al., 2014), there was no evidence of immediate within-group punishment of individuals that did not contribute at all, or contributed less, as evidenced by a lack of any observed subordinate-directed aggression during the trials.

\section{Threat level experiment}

Data from the paired within-individual repeated measures experiment were analysed to investigate whether individual contributions are adjusted in response to the level of threat presented. Focusing on the dominant male and oldest subordinate male in each group, our analyses revealed that both classes of male responded significantly more rapidly to the high territorial threat treatment (non-neighbour duet playback) than to the low territorial threat treatment (neighbour duet playback; Table 2, Fig. 2a, b). Dominant males responded more rapidly than their subordinate counterparts under both treatments (Table 2, Fig. 2a, b) and there was no significant interaction between treatment and status (Table 2, Fig. 2a, b), indicating that both dominants and subordinates similarly 'stepped up' their responses under higher threat, leaving the dominance difference maintained under both scenarios. After the trial, all males took significantly longer to return to terrestrial foraging behaviour following the high territorial threat treatment (non-neighbour duet playback) than following the low

411 territorial threat treatment (neighbour duet playback; Table 2, Fig. 2c, d) and dominant males

412 took consistently longer than their subordinates (Table 2, Fig. 2c, d). Again, the more 
413 persistent response to the higher threat treatment was due to both dominant and subordinate

414 males taking a similarly greater amount of time to return to foraging in this context, as no

415 significant interaction between treatment and status was present (Table 2, Fig. 2c, d).

416

417 Regarding the overall group response to the threat manipulation, a significantly larger 418 proportion of group members contributed to the first vocal chorus in response to the high-

419 threat treatment than the low-threat treatment (GLMM: $\chi^{2}{ }_{1}=16.37, P<0.001$; Fig. $\left.3 \mathrm{a}\right)$.

420 Groups also produced significantly longer vocal choruses during the first response to the

421 high-threat treatment than during the first response to the low-threat treatment (LMM: $\chi^{2}{ }_{1}=$ $422 \quad$ 11.26, $P<0.001$; Fig. 3b).

423

424 Discussion

425 Contributing to competition between rival groups is predicted to occur in a payoff-dependent 426 manner with dominant individuals contributing most to territory defence, when within-group 427 social hierarchy determines the nature of individual benefits from defending a territory

428 (Gavrilets \& Fortunato, 2014). Our results in white-browed sparrow-weavers support this 429 prediction, as dominant individuals were significantly more likely than subordinates to 430 contribute to the first response to simulated territorial intrusions (probably the riskiest phase; 431 Heinsohn \& Packer, 1995), responded with shorter latencies and were slower to return to 432 foraging following such intrusions. While the majority of group members did eventually join 433 the collective territorial response to intrusions, a small proportion of subordinate individuals 434 failed to contribute at all and seemed to do so consistently across repeat trials. The 435 withholding of contributions by subordinates could call into question the benefits to 436 dominants of tolerating the presence of subordinates within their territories, which is widely 437 assumed to play an important role in the evolution of group living (Kingma, et al., 2014). 
438 However, our results also suggest that subordinates increase their contributions when they are

439 needed most: individual subordinates were more likely to contribute to the first response to a

440 territorial intrusion when in smaller groups, and subordinates responded faster (and were

441 slower to return to foraging) when faced with territorial intrusions designed to be indicative

442 of a higher level of threat. Flexibility in subordinate contributions in relation to the scale of

443 the threat could thereby help to explain the benefits of tolerating subordinates on the territory,

444 despite their unequal contributions to defence.

446 Public goods theory predicts that 'privileged' individuals should contribute more to the

447 cooperative defence of territory against rivals as they stand to benefit more from effective

448 territorial defence, since their contributions in territory defence can be viewed as competition

449 with their dominant counterparts in rival groups (Gavrilets \& Fortunato, 2014). While the

450 higher contributions of dominants in our study may well have arisen for precisely this reason,

451 additional or alternative mechanisms could also be at play. Dominant white-browed sparrow-

452 weavers are likely to gain greater fitness benefits from territorial retention than subordinates, since they monopolize reproduction (Harrison, York, Cram, Hares, \& Young, 2013; Harrison,

454 York, Cram, \& Young., 2013) and may also dominate competition for resources within the territory. However, as more competitive individuals, dominants could also experience lower costs of contributing to territorial defence (e.g. arising from a reduced risk of injury should the interaction escalate to physical aggression) than subordinates, which could also explain their higher contributions. Indeed, Gavrilets and Fortunato (2014) highlighted that it is the status-related differences in net payoff from contributions that should lead to 'privileged' individuals contributing more to collective territorial defence, which allows for the possibility

461 that status-related differences in both benefits and costs could contribute to this pattern. It is 462 also worth noting that while the use of a shared territory can be considered a public good (as 
all group members use the resources therein and hence stand to benefit from its collective defence), in reality territorial intrusions could threaten some group members' access to the

465 public good more than others. For example, in sparrow-weaver societies, while long-term 466 monitoring of territory boundaries suggests that territorial interactions among groups impact

467 territory size (and hence potentially affecting all group members, as envisaged in a standard 468 public goods scenario), such interactions also entail a threat of dominance takeover, in which extragroup individuals depose and evict resident dominants (Martin-Taylor, 2018). In this latter scenario, subordinates may be able to remain within the group (and hence continue to use the public good) while the previous dominant is invariably evicted (Martin-Taylor, 2018). Such a dominance-related difference in the extent to which outsiders threaten an individual's access to the public good (i.e. more so for dominants than subordinates in this case) could therefore also help to explain the higher contributions of dominants observed in this study.

476 Given our results that subordinates do contribute to group territory defence (albeit at lower

477 levels than dominants) and that dominants monopolize within-group reproduction, what benefit(s) might subordinates accrue from contributions to defence? As envisaged in public goods scenarios (see above), subordinates in this and other species are likely to gain direct fitness benefits from the effective defence of the shared territory, in both the short term (e.g. via benefits of residing on a familiar territory within the family unit; Ekman \& Griesser, 482 2002) and the longer term (e.g. given their downstream potential to secure a breeding position 483 within the territory; Woolfenden \& Fitzpatrick, 1978; Harrison et al 2014). In cooperatively breeding species, such as white-browed sparrow-weavers, the vast majority of subordinate individuals are offspring from previous generations that have not dispersed and hence are engaging in the cooperative defence of territory alongside related dominants (typically their

487 parents; Bergmüller et al., 2007; Cockburn, 1998; Hatchwell, 2009; Lukas \& Clutton-Brock, 
2012). Subordinates within their natal groups may thereby also stand to gain indirect fitness benefits from defending the territory's resources (a public good) for use by relatives, and by defending the dominants themselves (and their future reproductive success) from

491 displacement by unrelated extragroup individuals (Hatchwell, 2009). Indeed, the indirect

492 benefits to subordinates of contributions to territorial defence are likely to be an important 493 source of selection for the maintenance of subordinate contributions to territory defence in cooperatively breeding societies, in addition to the direct benefits that are typically the focus of public goods scenarios (Duncan et al., 2019; Gavrilets \& Fortunato, 2014; Hatchwell, 2009). While we did not investigate the extent to which individual variation in inclusive

497 fitness payoffs from investment in territorial defence explains individual variation in subordinate contributions for our focal species in this study, the lack of a sex difference in the probability that subordinates inherit the breeding position within their natal groups (Harrison et al., 2014), coupled with the likely lack of a sex difference between subordinates in the indirect benefits to be accrued from defence of the natal territory, could explain why we found no evidence here of a clear sex difference in subordinate contributions to territory defence.

505 Failure to contribute sufficiently to the maintenance of a public good by subordinates could 506 be met with punishment (Bergmüller et al., 2007; Bshary \& Bergmüller, 2008). Indeed, in 507 some cooperatively breeding societies, subordinates are thought to 'pay to stay', a scenario in 508 which the dominant's toleration of their presence within the territory is contingent upon their cooperative contributions, with failure to contribute being punished with aggressive eviction

510 (Zöttl et al., 2013). However, we found no evidence of immediate overt punishment (via

511 within-group behavioural aggression) in our study despite variation in subordinate

512 contributions that could attract punitive aggression by dominants. It is conceivable, however, 
513 that such aggression was delayed and therefore would not have been observed during the

514 trials. Moreover, the threat of punishment could conceivably have played a role in the

515 maintenance of cooperation at the levels observed in this study, as individual subordinates

516 could have maintained their contributions at the level required to avoid eliciting punishment

517 (Cant \& Young 2013). While punishment is a frequently observed mechanism enforcing 518 cooperation in humans, it is much more rarely observed in animal societies (Raihani et al.,

519 2012; Riehl \& Frederickson, 2016). It is possible that, because adaptive cheating in nature is

520 often at low frequencies in populations due to frequency-dependent selection, or because

521 uncooperative individuals experience lower fitness (Riehl \& Frederickson, 2016), punishment

522 in the form of using aggression to enforce cooperation need only arise in a very limited set of

523 circumstances (e.g. in social groups in which relatedness is typically low).

525 Some caution is needed in the interpretation of cooperative contributions to any territorial

526 defence activities that do not involve immediate engagement in fighting with extragroup

527 individuals, as some resident members could contribute to a movement, vigilance and/or

528 vocal response not because they intend to contribute to a collective aggressive repulsion of

529 rival intruders, as is often envisaged in theoretical and empirical studies, but instead because

530 approaching, assessing or advertising to intruders could offer resident individuals other

531 benefits (e.g. if intruders constitute potential mates; Thompson \& Cant, 2018). This is a

532 challenge for such studies but needs to be more widely acknowledged. Indeed, this highlights

533 a possible need for caution in interpretation of the outcomes of our territory 'threat'

534 manipulation experiment in the current study. While unfamiliar non-neighbouring pairs are

535 likely to pose a greater threat than established neighbours (because of the higher risk of

536 territory takeover), our finding of stronger territorial responses by both subordinates and

537 dominants in this context could reflect the possibility that individuals show differential 
interest in the unfamiliar birds whose vocalizations are being presented (e.g. as potential immediate or future mates). However, in our focal species, both within- and between-group

540 reproduction is monopolized by dominant individuals, and dominant males sing a separate

541 song repertoire in solo performances in sexual contexts primarily at dawn, which suggests

542 that reproductive and territorial information exchange are conducted via discrete channels in this system, making an 'information-gathering' function of intergroup encounters less likely

544 to play the primary role in individual responses to territory intrusions (Collias \& Collias, 1978; Collias \& Collias, 2004; Voigt, Leitner, \& Gahr, 2005; Walker et al., 2016; York, 2012; York et al., 2016). Furthermore, all our data were collected outside the context of breeding activity for the focal groups; therefore, if any sexually selected benefits of attending to information during intergroup encounters do exist, these benefits would be of low reward in the context of this specific study.

Our findings suggest that subordinates contribute less to territorial defence than dominants, and that their contributions appear to decrease with increases in their group size. These

553 findings highlight that while dominants may indeed accrue territorial defence benefits from tolerating the presence of additional subordinates, these benefits may be more modest than is generally appreciated as each subordinate contributes less as group size increases. As selection for helping to rear the offspring of dominants is also frequently thought to arise in part from direct benefits to helpers resulting from the territorial gains to be accrued from rearing more group members (the group augmentation hypothesis; Woolfenden \& Fitzpatrick, 1978; Kingma et al., 2014), the benefits of helping behaviour that arise through this mechanism could also be more modest than is generally recognized. However, our findings

561 do also suggest that subordinates increase their contributions when they are needed most, and 562 this context dependence might thereby underpin the territorial benefits to be accrued from 
additional subordinates, perhaps particularly so when faced with larger opposition groups

564 (Packer, Scheel, \& Pusey, 2002). While all simulated territorial intrusions in this study

565 involved the playback of duets recorded from a breeding pair (simulating an intruder group

566 size of two), note that white-browed sparrow-weaver groups range from two to 12

567 individuals, and larger groups have larger territories and appear to outcompete neighbours for 568 space (Martin-Taylor, 2018). Consequently, it is possible that subordinates in large groups

569 (which were unlikely to contribute to the first territorial response in our study, when faced

570 with a simulated intrusion by a pair; Fig. 1) would increase their contributions when faced

571 with intrusions by numerically larger opponents, if neighbouring resident groups compete

572 directly over territory and larger groups reflect a more significant threat to their territory.

573 Investigating this possibility, and its implications for the patterns of selection that arise from

574 intergroup conflict, may provide an avenue for future research.

576 We do not yet know the extent to which individual contributions to cooperative territory

577 defence in white-browed sparrow-weavers are individually consistent, although our results do 578 suggest that they may be consistent under the same context, but express flexibility between 579 different contexts. Consistent individual differences in subordinate white-browed sparrow580 weavers could underlie different classes of 'contributor' phenotypes and thereby explain the 581 presence of individuals that never contributed to group territory defence in the context of 582 simulated territory intrusions. For example, cooperatively nesting greater ani, Crotophaga

583 major, appear to have two types of consistent cooperative strategies in the context of 584 communal nesting: either never cheat ('pure cooperative' strategy) or cooperate and cheat 585 ('mixed' strategy), which demonstrates that cooperation and cheating can coexist stably in 586 the same population via individual tactics (Riehl \& Strong, 2019). Similarly, female lions

587 (Panthero leo) exhibit individual differences in their contributions to group territory defence 
588 (Heinsohn \& Packer, 1995) and cooperatively breeding meerkats, Suricata suricatta, and banded mongooses, Mungos mungo, show consistent individual differences in offspring care

590 (English, Nakagawa, \& Clutton-Brock, 2010; Sanderson et al., 2015).

591

592 In summary, our findings contribute to a wider body of evidence suggesting that dominants

593 frequently contribute more to territorial defence than subordinates and in so doing are consistent with, and hence lend support to, the predictions of economic theory that privileged individuals contribute more. Where subordinates contribute less, our findings suggest that they may nevertheless step up when needed most, and this plasticity may in part underpin

597 their continued toleration by dominants.

598

Author Contributions

600 J.E.Y. and A.J.Y. conceived and designed the study. J.E.Y. and K.J.W. performed field data 601 collection. J.E.Y. conducted data analysis. J.E.Y. and A.J.Y. wrote the manuscript.

602

603

\section{Data Availability}

604 Data are available at the Mendeley repository: http://dx.doi.org/10.17632/trb75pkfyk.1

605

606 Declaration of Interest

607 We declare no conflict of interest.

608

609 Acknowledgments

610 This study was funded by a Biotechnology and Biological Sciences Research Council David

611 Phillips Research Fellowship (BB/H022716/1) to A.J.Y. We thank all contributors to our

612 long-term fieldwork, especially Lindsay Walker and Dominic Cram, Tswalu Kalahari 
613 Reserve for logistical support and site access, Tom Houslay and especially Dominic Cram for

614 helpful discussions, and two anonymous referees for helpful comments.

615

616 References

617 Amrhein, V., Greenland, S., \& Mcshane, B. (2019). Retire statistical significance. Nature, $618567,305-307$.

619 Arseneau-Robar, T. J. M., Müller, E., Taucher, A. L., Van Schaik, C. P., Bshary, R., \& 620 Willems, E. P. (2018). Male monkeys use punishment and coercion to de-escalate costly 621 intergroup fights. Proceedings of the Royal Society B: Biological Sciences, 285 (1880). doi.org/10.1098/rspb.2017.2323

623

Bates, D., Maechler, M., \& Bolker, B. (2014). lme4: linear mixed-effects models using S4 624

625 classes. R package version 1.1-7. R. http://doi.org/http://CRAN.Rproject.org/package $=1 \mathrm{me} 4$

Bergmüller, R., Russell, A. F., Johnstone, R., \& Bshary, R. (2007). On the further integration of cooperative breeding and cooperation theory. Behavioural Processes, 76 (2), 170-81. doi.org/10.1016/j.beproc.2007.06.013

Bonanni, R., Valsecchi, P., \& Natoli, E. (2010). Pattern of individual participation and cheating in conflicts between groups of free-ranging dogs. Animal Behaviour, 79 (4), 957-968. doi.org/10.1016/j.anbehav.2010.01.016

Bshary, R., \& Bergmüller, R. (2008). Distinguishing four fundamental approaches to the evolution of helping. Journal of Evolutionary Biology. doi.org/10.1111/j.14209101.2007.01482.x public good in reef fishes. Current Biology, 20 (22), 2032-2035. doi.org/10.1016/j.cub.2010.10.027 
638 Cant, M. \& Young A.J. (2013). Resolving social conflict among females without overt 639 aggression. Philosophical Transactions of The Royal Society B: Biological Sciences, 368 $640 \quad(1631): 20130076$.

641 Christensen, C., \& Radford, A. N. (2018). Dear enemies or nasty neighbors? Causes and 642 consequences of variation in the responses of group-living species to territorial 643 intrusions. Behavioral Ecology, 29 (5), 1004-1013. doi.org/10.1093/beheco/ary010

644 Clutton-Brock, T. H., \& Parker, G. A. (1995). Punishment in animal societies. Nature, 645 373(6511), 209-16. doi.org/10.1038/373209a0

646 Cockburn, A. (1998). Evolution of helping behaviour in cooperatively breeding birds. Annual 647 Review of Ecological Systems, 29, 141-177. doi.org/10.1146/annurev.ecolsys.29.1.141 648 Collias, N. E., \& Collias, E. C. (1978). Cooperative breeding behavior in the white-browed 649 sparrow weaver. The Auk, 95, 472-484. doi.org/10.1093/auk/95.3.472

650 Collias, N. E., \& Collias, E. C. (2004). Comparison of vocal signals of three species of $651 \quad$ African finches. Behaviour, 141, 1151-1171.

652 Cords, M. (2007). Variable participation in the defense of communal feeding territories by 653 blue monkeys in the Kakamega Forest, Kenya. Behaviour, 144, 1537-1550. 654 doi.org/10.1163/156853907782512100

655

Crofoot, M. C., \& Gilby, I. C. (2012). Cheating monkeys undermine group strength in enemy 656 territory. Proceedings of the National Academy of Sciences of the United States of America, 109(2), 501-505. doi.org/10.1073/pnas.1115937109

Dugatkin, L. (1997). Cooperation Among Animals: An Evolutionary Perspective. Oxford, 659 U.K.: Oxford University Press.

660 Duncan, C., Gaynor, D., Clutton-Brock, T., \& Dyble, M. (2019). The Evolution of 661 Indiscriminate Altruism in a Cooperatively Breeding Mammal. The American $662 \quad$ Naturalist, 193, 841-851. doi.org/10.1086/703113 
Ekman, J. \& Griesser, M. 2002. Why offspring delay dispersal: experimental evidence for a role of parental tolerance. Proceedings of the Royal Society B: Biological Sciences, 269:

665 17091713.

English, S., Nakagawa, S., \& Clutton-Brock, T. H. (2010). Consistent individual differences in cooperative behaviour in meerkats (Suricata suricatta). Journal of Evolutionary Biology, 23 (8), 1597-604. doi.org/10.1111/j.1420-9101.2010.02025.x

Fehr, E., \& Fischbacher, U. (2004). Social norms and human cooperation. Trends in Cognitive Sciences, 8 (4), 185-190. doi.org/10.1016/j.tics.2004.02.007

Forstmeier, W., \& Schielzeth, H. (2011). Cryptic multiple hypotheses testing in linear models: Overestimated effect sizes and the winner's curse. Behavioral Ecology and Sociobiology, 65 (1), 47-55. doi.org/10.1007/s00265-010-1038-5

Gavrilets, S., \& Fortunato, L. (2014). A solution to the collective action problem in betweengroup conflict with within-group inequality. Nature Communications, 5, 1-11. doi.org/10.1038/ncomms4526

Griesser M., Drobniak S.M., Nakagawa S., Botero C.A. (2017) Family living sets the stage for cooperative breeding and ecological resilience in birds. PLoS Biology 15 (6): e2000483. doi.org/10.1371/journal.pbio.2000483

Hager, R., \& Jones, C. B. (2009). Reproductive Skew in Vertebrates: Proximate and Ultimate causes. Cambridge, U.K.: Cambridge University Press.

Harrison, X. A., York, J. E., Cram, D. L., Hares, M. C., \& Young, A. J. (2013). Complete reproductive skew within white-browed sparrow weaver groups despite outbreeding opportunities for subordinates of both sexes. Behavioral Ecology and Sociobiology, 67 (12), 1915-1929. doi.org/10.1007/s00265-013-1599-1 
Harrison, X. A., York, J. E., \& Young, A. J. (2014). Population genetic structure and direct observations reveal sex-reversed patterns of dispersal in a cooperative bird. Molecular Ecology, 23 (23), 5740-55. doi.org/10.1111/mec.12978

Hartig, F. (2016). DHARMa: Residual Diagnostics for Hierarchical (Multi-Level / Mixed) Regression Models. R package version 0.2.0. https://CRAN.Rproject.org/package=DHARMa.

Hatchwell, B. J. (2009). The evolution of cooperative breeding in birds: kinship, dispersal and life history. Philosophical Transactions of the Royal Society of London. Series B: Biological Sciences, 364 (1533), 3217-27. doi.org/10.1098/rstb.2009.0109

Heinsohn, R., \& Packer, C. (1995). Complex cooperative strategies in group-territorial African lions. Science, 269 (5228), 1260-1262. doi.org/10.1126/science.7652573

Johnson, D. D. P. (2005). God's punishment and public goods. Human Nature, 16 (4), 410446. doi.org/10.1007/s12110-005-1017-0

Keller, L., \& Reeve, H. K. (1994). Partitioning of reproduction in animal societies. Trends in Ecology and Evolution, 9 (3), 98-102. doi.org/10.1016/0169-5347(94)90204-6

Kingma, S. A., Santema, P., Taborsky, M., \& Komdeur, J. (2014). Group augmentation and the evolution of cooperation. Trends in Ecology \& Evolution, 29 (8), 476-484. doi.org/10.1016/j.tree.2014.05.013

Kitchen, D., \& Beehner, J. (2007). Factors affecting individual participation in group-level aggression among non-human primates. Behaviour, 144 (12), 1551-1581. doi.org/10.1163/156853907782512074

Lewis, D. M. (1982). Cooperative breeding in a population of white-browed sparrow weavers Plocepasser mahali. Ibis, 124, 511-522. doi.org/10.2307/1367373

712 Lukas, D., \& Clutton-Brock, T. (2012). Cooperative breeding and monogamy in mammalian 
societies. Proceedings of the Royal Society B: Biological Sciences, 279 (1736), 2151-6. doi.org/10.1098/rspb.2011.2468

715

716

717

718

719

720

721

722

723

724

725

726

727

728

729

730

731

732

733

734

735

736

737

Mares, R., Young, A. J., \& Clutton-Brock, T. H. (2012). Individual contributions to territory defence in a cooperative breeder: weighing up the benefits and costs. Proceedings of the Royal Society B: Biological Sciences, 279 (1744), 3989-95. doi.org/10.1098/rspb.2012.1071

Mares, R., Young, A. J., Levesque, D. L., Harrison, N., \& Clutton-Brock, T. H. (2011). Responses to intruder scents in the cooperatively breeding meerkat: sex and social status differences and temporal variation. Behavioral Ecology, 22 (3), 594-600. doi.org/10.1093/beheco/arr021

Martin-Taylor, C. M. (2018). The impacts of out-group threats on within- and between-group behaviours in the cooperatively breeding white-browed sparrow weaver. [M.Sc. by Research thesis]. Penryn, U.K.: University of Exeter.

Nunn, C. (2000). Collective benefits, free-riders, and male extra-group conflict. In Kappeler, P. M. (Eds) Primate Males: Causes and Consequences of Variation in Group Composition (pp. 192-204). Cambridge, U.K.: Cambridge University Press.

Nunn, C. L., \& Lewis, R. J. (2001). Cooperation and collective action in animal behaviour. In J. A. R. A. M. Van Hooff, P. Hammerstein, \& R. Noë (Eds.), Economics in Nature: Social Dilemmas, Mate Choice and Biological Markets (pp. 42-66). Cambridge, U.K.: Cambridge University Press.

Nunn, C. L., \& Deaner, R. O. (2012). Patterns of participation and free riding in territorial conflicts among ringtailed lemurs. Behavioral Ecology and Sociobiology, (Lemur catta), 57 (1), 50-61. doi.org/10.1007/S00265-004-0830-5

Olson, M. (1965). The Logic of Collective Action: Public Goods and the Theory of Groups. Cambridge, MA: Harvard University Press. 
Packer, C., Scheel, D., \& Pusey, A. E. (2002). Why Lions Form Groups: Food is Not Enough. The American Naturalist, 136 (1), 1-19. doi.org/10.1086/285079

R Core Team. 2015. R: a language and environment for statistical computing. Vienna, Austria: R Foundation for Statistical Computing. http://www.R-project.org/.

Raihani, N. J., Grutter, A. S., \& Bshary, R. (2010). Punishers benefit from third-party punishment in fish. Science, 327 (5962). doi.org/10.1126/science.1183068

Raihani, N. J., Thornton, A., \& Bshary, R. (2012). Punishment and cooperation in nature. Trends in Ecology and Evolution, 27, 288-295. doi.org/10.1016/j.tree.2011.12.004

Ridley, A. R., Raihani, N. J. \& Nelson-Flower, M. J. (2008). The costs of being alone: the fate of floaters in a population of cooperatively breeding pied babblers Turdoides bicolor. Journal of Avian Biology, 39, 389-392.

Riehl, C., \& Frederickson, M. E. (2016). Cheating and punishment in cooperative animal societies. Philosophical Transactions of the Royal Society B: Biological Sciences, 371 (1687). doi.org/10.1098/rstb.2015.0090

752

Riehl, C., \& Strong, M. J. (2019). Social parasitism as an alternative reproductive tactic in a cooperatively breeding cuckoo. Nature, 567 (7746), 96-99. doi.org/10.1038/s41586019-0981-1

Sanderson, J. L., Stott, I., Young, A. J., Vitikainen, E. I. K., Hodge, S. J., \& Cant, M. A. (2015). The origins of consistent individual differences in cooperation in wild banded mongooses, Mungos mungo. Animal Behaviour, 107, 193-200. doi.org/10.1016/j.anbehav.2015.06.022

Sigmund, K., De Silva, H., Traulsen, A., \& Hauert, C. (2010). Social learning promotes institutions for governing the commons. Nature, 466 (7308), 861-863. doi.org/10.1038/nature09203

Temeles, E. J. (1994). The role of neighbours in territorial systems: when are they 'dear 
764 Therneau, T. M. (2015). coxme: Mixed Effects Cox Models. R package. https://cran.rproject.org/package $=$ coxme

Thompson, F. J., \& Cant, M. A. (2018). Dynamic conflict among heterogeneous groups: a comment on Christensen and Radford. Behavioral Ecology, 29 (5), 1016-1017. doi.org/10.1093/beheco/ary044

van Schaik, C. P. (1996). Social evolution in primates: the role of ecological factors and male behaviour. Proceedings of the British Academy, 88, 9-31.

Voigt, C., Leitner, S., \& Gahr, M. (2006). Repertoire and structure of duet and solo songs in cooperatively breeding white-browed sparrow weavers. Behaviour, 143, 159-182.

773

774

775

776

777

778

779

780

781

782

783

784

785

786

787

Walker, L. A., York, J. E., \& Young, A. J. (2016). Sexually selected sentinels? Evidence of a role for intrasexual competition in sentinel behavior. Behavioral Ecology, 27 (5), 14611470. doi.org/10.1093/beheco/arw064

West, S. A., \& Gardner, A. (2004). Cooperation and punishment, especially in humans. The American Naturalist, 164, 753-764.

Wingfield, J. C., Hegner, R. E., \& Lewis, D. M. (1992). Hormonal responses to removal of a breeding male in the cooperatively breeding white-browed sparrow weaver, Plocepasser mahali. Hormones and Behavior, 26 (2), 145-55.

Wingfield, J. C., \& Lewis, D. M. (1993). Hormonal and behavioural responses to simulated territorial intrusion in the cooperatively breeding white-browed sparrow weaver, Plocepasser mahali. Animal Behaviour, 45, 1-11.

Woolfenden, G. E., \& Fitzpatrick, J. W. (1978). The Inheritance of Territory in GroupBreeding Birds. BioScience, 28 (2), 104-108. doi.org/10.2307/1307423

York, J. (2012). The evolution and regulation of dawn song performance in white-browed sparrow weaver society. [Ph.D thesis]. Bristol, U.K.: University of Bristol. 
York, J., Young, A., \& Radford, A. (2014). Singing in the moonlight: dawn song performance of a diurnal bird varies with lunar phase. Biology Letters, 10, 1-4.

790 doi.org/10.1098/rsbl.2013.0970

York, J., Radford, A., Groothuis, T, \& Young, A. (2016). Dominant male song performance reflects current immune state in a cooperatively breeding songbird. Ecology and Evolution, 6(4): 1008-1015. doi.org/10.1002/ece3.1938

794 York, J., Radford, A., Vries, B. de, Groothuis, T, \& Young, A. (2016). Dominance-related 795 seasonal song production is unrelated to circulating testosterone in a subtropical songbird. General and Comparative Endocrinology, 233, 43-52. doi.org/10.1016/j.ygcen.2016.05.011

York, J. (2019). 'Data for 'Dominance-related contributions to collective territory defence are 799 adjusted according to the threat', Mendeley Data, V1, doi: 10.17632/trb75pkfyk.1

800 York, J. (n.d.). Unpublished raw data (Longitudinal ad libitum behavioural observations)

801 Zöttl, M., Heg, D., Chervet, N., \& Taborsky, M. (2013). Kinship reduces alloparental care in 802 cooperative cichlids where helpers pay-to-stay. Nature Communications, 4, 1341.

$803 \quad$ doi.org/10.1038/ncomms2344 
806 Individual contributions to simulated territorial intrusions

Response term

Probability of contributing during first response (Yes/No)

Probability of contributing during trial (Yes/No)

$\begin{array}{rccc}\text { Explanatory terms } & \text { Estimate } \pm \mathrm{SE} & \chi^{2} & P \\ & & & \\ \text { Status: subordinate } & 0.34 \pm 2.16 & 40.09 & <0.001 \\ \text { Group size } & -0.01 \pm 0.36 & 0.00 & 1.00 \\ \text { Sex: male } & -0.40 \pm 0.70 & 0.42 & 0.517 \\ \text { Group size* status } & -0.85 \pm 0.63 & 3.77 & 0.052 \\ \text { (Intercept) } & 3.22 \pm 2.12 & & \\ & & & \\ \text { Bird ID } & 2.76 \pm 1.66 & & \\ & & & 0.37 \\ \text { Status: subordinate } & 7.08 \pm 10.86 & 0.82 & 0.64 \\ \text { Group size } & 1.87 \pm 3.10 & 0.21 & 0.96 \\ \text { Sex: male } & -0.09 \pm 1.82 & 0.003 & 0.31 \\ \text { Group size*status } & -2.30 \pm 3.18 & 1.01 & \\ \text { (Intercept) } & 4.12 \pm 9.72 & & \\ & & & \\ \text { Bird ID } & 365.6 \pm 19.12 & & \end{array}$

807

808 The $P$ value for each term is based on the chi-square test (likelihood ratio test) for change in

809 deviance when comparing models with or without that term (given the borderline significance

810 of the Group size*status interaction, we also report the $\chi^{2}$ and $P$ values for the Status and

811 Group size terms in isolation, following removal of the interaction, to aid interpretation). The

812 mean estimates $\pm \mathrm{SE}$ are reported for all terms in the full model. GLMM: generalized linear

813 mixed-effects model. GLMM estimates are raw values from model (logit-link function).

814 Variance and SD are reported for the random term Bird ID. 


\section{Table 2}

816 Dominant and subordinate male responses to experimental manipulation of the scale of the

817 territory threat

818

Response term

Latency to

first response

Latency to

resume foraging

819

$\begin{array}{rccc}\text { Explanatory terms } & \text { Estimate } \pm \mathrm{SE} & \chi^{2} & P \\ & & & \\ \text { Treatment*status } & 1.06 \pm 0.98 & 1.34 & 0.25 \\ \text { Treatment: non-neighbour } & 2.08 \pm 0.60 & 29.69 & <0.001 \\ \text { Status: subordinate } & -2.08 \pm 0.85 & 9.96 & 0.002 \\ \text { Bird ID } & <0.001 \pm 0.020 & & \\ \text { Group } & 1.78 \pm 1.33 & & \\ & & & 0.66 \\ \text { Treatment*status } & -0.30 \pm 0.66 & 0.19 & 0.02 \\ \text { Treatment: non-neighbour } & -0.59 \pm 0.47 & 5.45 & 0.009 \\ \text { Status: subordinate } & 1.06 \pm 0.47 & 6.80 & \\ \text { Bird ID } & <0.001 \pm 0.019 & & \\ \text { Group } & 0.32 \pm 0.57 & & \end{array}$

820 The $P$ value for each term is based on the chi-square test (likelihood ratio test) for change in

821 deviance when comparing models with or without that term. The mean estimates $\pm \mathrm{SE}$ are

822 reported for all terms in the full model. Variance and SD are reported for the random terms 823 Bird ID and Group.

824 


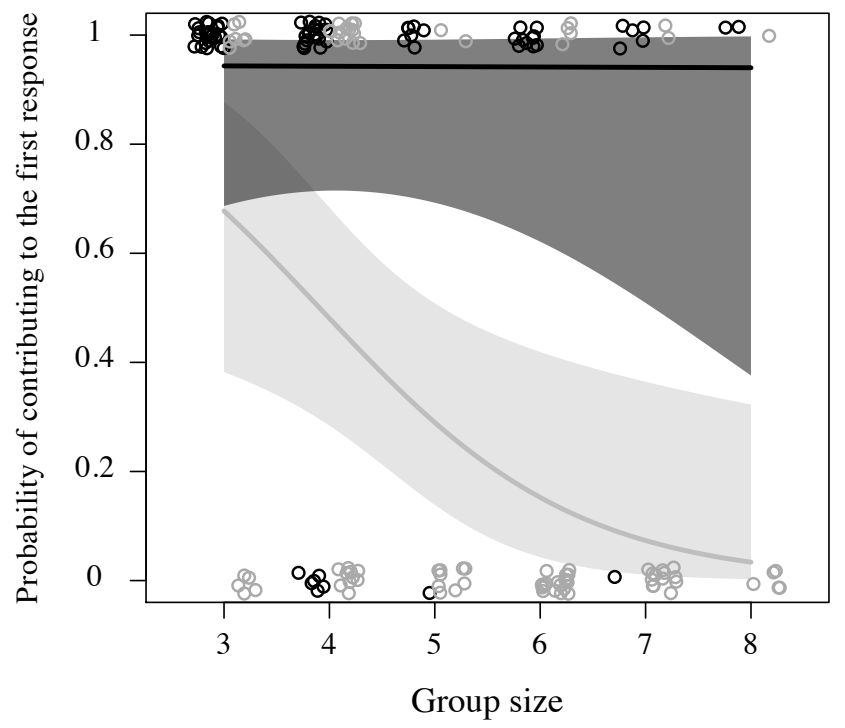

826

827 Figure 1. Individual contributions to simulated territorial intrusions in relation to social status

828 and group size. The probability of white-browed sparrow-weaver (dominants: black circles;

829 subordinates: grey circles) contributions to group territory defence, in relation to group size

830 (lines show predicted probabilities of responding and grey shading represents $95 \%$

831 confidence intervals from a GLMM with the variables of group size, social status and their

832 interaction as fixed effects, and bird identity fitted as a random term). 
(a) Dominant

(a) Subordinate

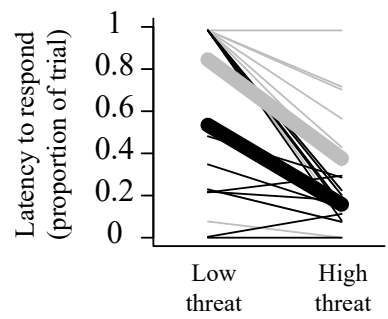

(c)

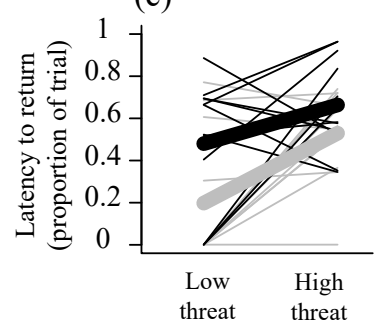

Treatment (b) All trials

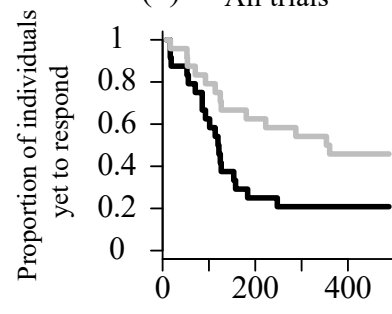

(d)
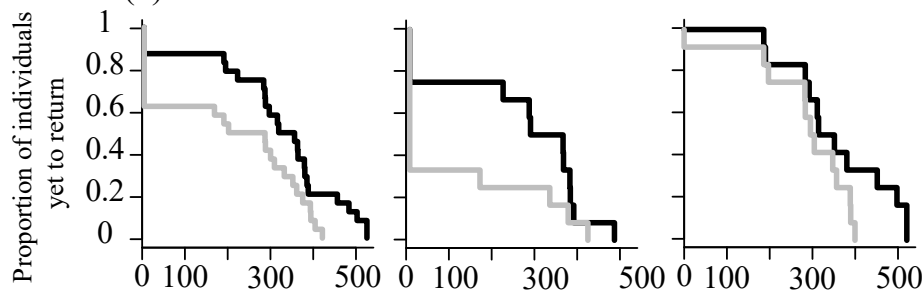

Time (sec)

834 Figure 2. Dominant and subordinate male responses to experimental manipulation of the

835 scale of the territory threat. (a) Paired data (thicker bars represent raw mean) showing latency

836 to the first response from each dominant (black) and subordinate (grey) male during

837 simulated intrusion of high threat (non-neighbour duet) or low threat (neighbour duet). (b)

838 Proportion of focal males (dominants: black; subordinates: grey) yet to show their first

839 response across the observation period ( 3 min playback trial followed by 5 min post-playback

840 observation) displayed for all trials, low-threat playbacks and high-threat playbacks. (c)

841 Paired data (thicker bars represent raw mean) showing latency to resume foraging for each

842 dominant (black) and subordinate (grey) male during simulated intrusion of high threat (non-

843 neighbour duet) or low threat (neighbour duet). (d) Proportion of focal males (dominants:

844 black; subordinates: grey) yet to resume foraging during the observation period displayed for

845 all trials, low-threat playbacks and high-threat playbacks. 


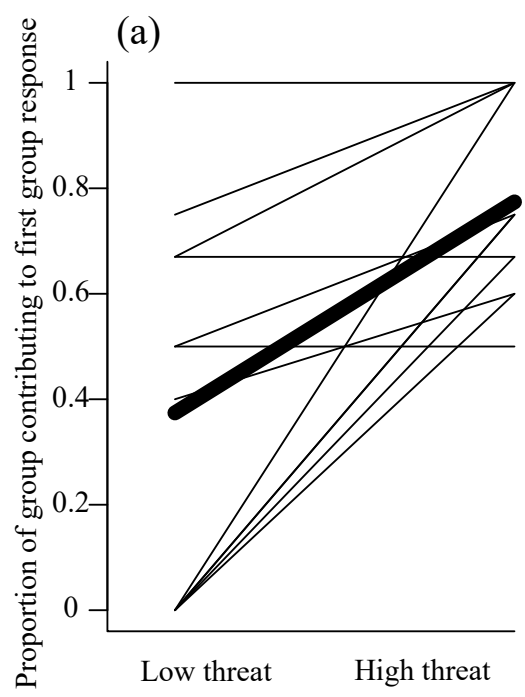

(b)

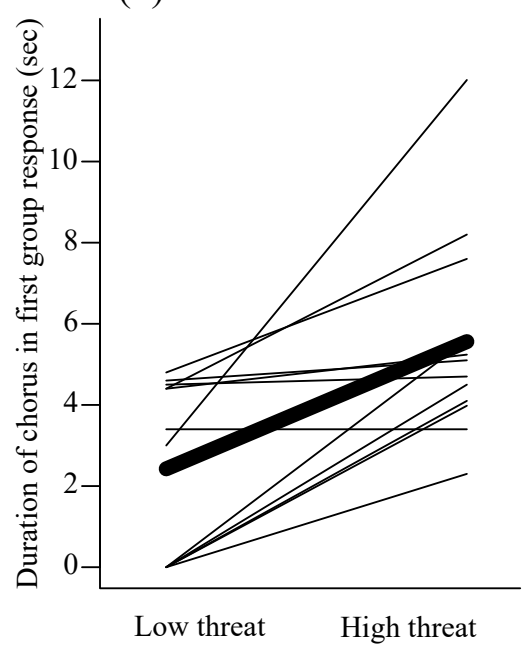

846

847 Figure 3. Overall group responses to experimental manipulation of the scale of the territory

848 threat. Paired contrasts of (a) the proportion of the group contributing to the first vocal chorus

849 response and (b) vocal chorus duration, under low and high threat. Means are shown as a

850 thicker black line. 